\title{
Kluge e debord: projeções entre escrita especulativa e produção \\ artística
}

Kluge and debord: speculative writing between projections and artistic production

\author{
Augusto SARMENTO-PANTOJA ${ }^{1}$ \\ (Universidade Federal do Pará) \\ Tânia SARMENTO-PANTOJA ${ }^{2}$ \\ (Universidade Federal do Pará)
}

Resumo: Este estudo pretende apresentar algumas ponderações acerca das relações entre escrita e produção artística. Nosso ponto de partida são as reflexões de Guy Debord, Alexander Kluge, este em diálogo com Jean Luc Godard, e suas respectivas produções cinematográficas.

Palavras-chaves: Alexander Kluge. Guy Debord. Cinema

Resumen: Este estudio tiene como objetivo presentar algunas consideraciones sobre la relación entre la escritura y la producción artística. Nuestro punto de partida son las reflexiones de Guy Debord, Alexander Kluge, este en diálogo con Jean Luc Godard, y sus producciones de cine.

Palabras-clave: Alexander Kluge. Guy Debord. Cinema

As imagens visíveis são fontes de inspiração para a produção literária, mas na literatura as imagens visíveis se cruzam com as não visíveis e estabelece com elas uma relação de mútua inspiração.

Karl Erik Schøllhammer ${ }^{3}$

\section{INTRODUÇÃO}

A imagem bem mais que a palavra, oral ou escrita, conseguiu articular no mundo contemporâneo não só o espaço de expressão mas, sobretudo, sua independência para com outras formas de arte e seus intercâmbios com o mundo do visível e do não-visível. Ao nos propormos a analisar a imagem podemos encontrar nela todas essas características que formam para esse objeto uma zona de conforto ôntico: a) a imagem que vemos; b) a imagem que queremos ver; c) a imagem que não queremos ver; d) a imagem do que não vemos.

Com base nesses quatro pontos, caminhamos para uma compreensão mais adequada de uma imagem, pois buscamos recorrer, no âmbito das análises do visível, a aspectos que, costumeiramente, ficam invisíveis a olho nu, o que não significa sua ausência e sim seu encobrimento, ora proposital, ora ocasional. Olhar a imagem em busca de desvelar o encoberto ou escamoteado faz com que tenhamos uma leitura mais ampla e completa dessa imagem, talvez por isso compreender os porquês desses encobrimentos se coloca como um desafio na escrita de alguns artistas, em particular naqueles envolvidos

\footnotetext{
1 Professor Assistente de Literatura Vernácula da Faculdade de Ciências da Linguagem, UFPA. Mestre em Estudos Literários pela UFPA e doutorando do Programa de Pós-Graduação Literatura e História Literária, UNICAMP. E-mail: augustos@ufpa.br

2 Professora Associada de Literatura Portuguesa da Faculdade de Letras e do Programa de Pós-Graduação em Letras da UFPA. Doutora em Estudos Literários, UNESP-Araraquara. E-mail: nicama@ufpa.br

3 Além do visivel: o olhar da literatura, p. 10 
com o cinema. Na medida em que atentamos para essas condições buscamos neste texto observar as variantes de leitura na produção escrita de dois grandes nomes do cinema moderno e as projeções dessas variantes sobre a imagem cinematográfica no século XX: respectivamente, Alexander Kluge e Guy Debord.

Alexander Kluge, cineasta, novelista, contista, que para Susan Sontag (apud KLUGE, 2010) poderia ser descrito simplesmente como "rumiante empedernido", por sua criação vigorosa. Sem dúvidas, podemos colocá-lo na condição de uma figura gigante da cultura alemã e um dos mais intensos e originais artistas-intelectuais surgidos na segunda metade do século XX. Nesse mesmo período desponta outro nome criativo que por sua autenticidade passa a ter espaço e destaque em textos acadêmicos e jornalísticos que buscam analisar e criticar a "sociedade da imagem" ou "do espetáculo" tal como foi analisada por ele: falamos de Guy Debord.

Debord compreende que vivemos em uma sociedade que por todos os lados nos bombardeia por ilusões que permeiam a vida cotidiana e transforma a realidade uma vez que a converte em encenação.

Debord e Kluge, em suas escritas especulativas, expressam o desafio de entender o pensamento moderno sobre o viés da imagem, ao ponto de observarmos que as concepções que apresentam relativamente ao manuseio da imagem se encontram imbuídas e referenciadas por suas ações enquanto produtores de conhecimento, seja por via artística (caso de Kluge), seja por via filosófica (caso de Debord), e se mostram envolvidas por um caráter autenticamente emancipador. Essa forma emancipadora de tratar sobre (e com) a imagem é mediada pela necessidade de lembrar, validar e perenizar as ideias subversivas que a sociedade moderna, em especial, a do espetáculo, insiste em nos fazer esquecer. Somos o tempo todo estimulados a esquecer o passado e de nós mesmos, em particular daquilo que fomos.

Em A Sociedade do Espetáculo, Guy Debord (1991) discute as estratégias espetaculares. Uma das primeiras teses defendidas por ele demarca que a sociedade pode ser entendida como um conjunto de eventos espetaculares, pois tudo é representável, neste sentido "o espetáculo em geral como inversão concreta da vida, é o movimento autônomo do não-vivo" (DEBORD, 1991, tese 2). Esse modo de ser da sociedade contemporânea procura nos fazer perceber de maneira ilusória o mundo, ao invés das representações menos líquidas da realidade. Ao apontar criticamente para essa condição Debord contribuí para a problematização sobre a verdade das imagens e consequentemente para a verdade da história.

Para compreendermos melhor esses enfrentamentos entre imagem, verdade e história confrontaremos duas formas particulares de escrita e crítica: de um lado, o livro 120 Histórias del cine de Alexander Kluge, ao qual tivemos acesso na tradução feita para o espanhol por Nicolás Gelormini. De outro lado, o já referido A Sociedade do Espetáculo, ensaio em que Guy Debord (1991, tese, 1) traça uma distinção fundamental em relação à natureza do espetáculo, ao considerar que "tudo o que era diretamente vivido se esvai na fumaça da representação". O paralelo entre as duas produções nos proporciona, de maneira ilustrativa, a possibilidade de pontuarmos marcas do discurso espetacular na cinematografia desses dois autores, observadas em Amor Cego - entrevista com Jean-Luc Godard (2001), de Alexander Kluge, e o filme homônimo A Sociedade do Espetáculo (1978), de Guy Debord.

Ao colocarmos em paralelo A Sociedade do Espetáculo - o livro e o filme observamos um conjunto de teorizações que pretendem analisar e compreender o cinema por meio do confronto entre cinema pensado e cinema executado. Nossa hipótese é a de que no material produzido por Kluge é possível encontrar a experimentação, no cinema, de posições políticas e críticas pensadas por Debord em sua escrita ensaística. Em outras palavras: um escreve pensando no cinema e o outro faz cinema pensando na escrita. Cada 
questão aqui apontada, de certo modo, será compreendida pelos trabalhos de ambos, uma vez que tanto os textos, quanto a cinematografia tornaram-se paradigmáticos para a compreensão das relações entre visibilidade e invisibilidade no espetáculo.

\title{
1 GUY DEBORD: UMA SOCIEDADE QUE MONTA E REMONTA O ESPETACULAR
}

A montagem e remontagem é um dos principais procedimentos de Debord para elaborar suas teses no filme $A$ Sociedade do Espetáculo ${ }^{4}$ na qual encontramos a viabilidade de uma leitura que ultrapassa a ideia de espetáculo e aponta para algo mais complexo, alcançando uma forma filosófica de pensar os mecanismos de visibilidade e invisibilidade na sociedade que Debord considerará espetacular, pelo fato de:

\begin{abstract}
O espetáculo submete a si os homens vivos, na medida em que a economia já os submeteu totalmente ele $\mathrm{n}$ ao é nada mais que a economia desenvolvendo-se para si mesma. É o reflexo fiel da produção das coisas, e a objetivação infiel dos produtores. Lá onde o mundo real se converte em simples imagens, as simples imagens tornam-se seres reais e motivações eficientes de um comportamento hipnótico. ${ }^{5}$
\end{abstract}

Observamos o confronto entre a visibilidade e a invisibilidade quando captamos da proposta cinematográfica e escrita de Debord essas duas perspectivas, definidas sob os liames reguladores desses conflitos sobre a imagem, principalmente ao considerar que "o espetáculo é o capital a um tal grau de acumulação que se torna imagem". (DEBORD, 1991, tese 34). Desse modo não temos como deixar de lado a proposição de $A$ sociedade do espetáculo, filme e livro, ao ponderar que:

O espetáculo não é um conjunto de imagens, mas uma relação social entre pessoas, medida por imagens. O espetáculo, compreendido na sua totalidade, é ao mesmo tempo o resultado e o projeto do modo de produção existente. Ele não é um suplemento ao mundo real, uma decoração adicionada. É o coração da irrealidade da sociedade real ${ }^{6}$

Nesses termos encontramos o corpo e o fetiche como válvulas propulsoras do desejo de consumo e da alienação provocados pelo efeito hipnótico do espetáculo, do capital e do desejo, vistos, nesse sentido, como partes de um todo mercantil, como salienta João Freire Filho (2003, p. 37, grifos do autor):

O conceito de espetáculo se refere tanto à experiência prática da realização (sem
obstáculos) dos desígnios da "razão mercantil" quanto às novas técnicas de
governo usadas para avançar o empobrecimento, a sujeição e a negação da vida
real e, como alertara Gramsci, conquistar o controle social por intermédio mais
do consenso do que da força.

Esse controle social que marca o empobrecimento, a sujeição e a negação da vida real será determinante em diversas perspectivas. A título de exemplo tomemos os regimes ditatoriais. Nas ditaduras a presença de um governo autoritário faz com que a sociedade seja envolvida por um controle, ao mesmo tempo tentacular e especialmente hipnótico, tal como proposto por Debord, ao comentar sobre a tendência da sociedade capitalista em

\footnotetext{
${ }^{4}$ DEBORD, Guy. A sociedade do espetáculo. Filme, Documentário, 88 min, França, 1973. As referências ao filme serão expressas pelo marcador de tempo (HH:MM:SS) e as do livro pela numeração referente a tese encontrada no livro. Vale lembrar que o filme possui o texto de Debord como estrutura narrativa.

5 A Sociedade do espetáculo, (0:06:23 - 0:06:51), tese 16 e 18

${ }^{6}$, A Sociedade do Espetáculo, (0:04:03 - 0:04:29), teses 4 e 6.
} 
privilegiar o consumo dos fetiches deixando de lado o entendimento real dos acontecimentos. Essa que pode ser compreendida como uma estratégia de construção de relações imagéticas interpostas sob o signo da visibilidade e da invisibilidade discutidas aqui, isso porque nem tudo o que desejamos enxergar pode ser visto, compreendido, aceito. Cria-se uma imagem que será divulgada para a sociedade em geral, que expressa o que deve ser mostrado e como será permitida a sua interpretação.

Em contraposição à visão unilateral que os regimes ditatoriais implementam sobre si mesmos, o testemunho será peça fundamental para compreendermos as farsas e disfarces defendidos por tais regimes, como se fossem a verdade. Podemos assim entender a posição de Debord quando considera que "o espetáculo, compreendido na sua totalidade, é simultaneamente o resultado e o projeto do mundo de produção existente" (DEBORD, 1991, tese 6). Desse modo, as narrativas antagônicas aos discursos de poder funcionarão como uma espécie de um dispositivo suplementar ao mundo real, já que possibilitam a ampliação de seu entendimento, por isso não podem ser compreendidos como um adereço decorativo. Seria uma espécie de discurso de realidade em uma sociedade irreal, mesmo quando não leva em conta a presença de um espectador.

Pensar em espetáculo exige um pouco mais de atenção. Para Debord (1991, tese 4) "o espetáculo não é um conjunto de imagens, mas uma relação social entre pessoas, mediatizada por imagens". Podemos dizer, de outro modo, que o espetáculo representa a relação social da imagem com aquele que vê. Se gera uma relação com o real, a relação daquele que assiste com o que é assistido, pois o que é assistido está ligado com a percepção de si mesmo, assim o indivíduo faz uma leitura do espetáculo como parte de sua própria vida.

Certamente há diferenças sensíveis entre as formas de expressão do texto e do cinema nesses dois autores-produtores, porém devemos destacar algumas estratégias peculiares a ambos e acentuar suas diferenças.

Quando nos detemos ao espaço da escrita de Kluge e Debord encontramos duas formas fragmentárias, construídas pela recorrência de temas e/ou fatos, que foram ordenados para gerar certa unidade. Por outro lado, são duas formas diferentes de estruturação de texto, pois Kluge, como veremos adiante, opta pela recuperação narrativa e Debord pela construção de aforismos e elucubrações.

No cinema de Debord não é diferente. Debord projeta em cenas espetaculares as guerras, a exploração do corpo, do trabalho, a expropriação das vidas pelo capital, tomando suas reflexões como ponto de partida para a análise de vários fragmentos de filmes que costuram a ânsia do homem por dominar e destruir outros homens. A estrutura fragmentária presente no filme segue o modelo da escrita e a raiz das reflexões de Debord encontram-se igualmente presentes em ambos. Destruir - e consumir - se torna um fetiche, sempre em estado de escamoteamento. Desse modo, o signo da destruição de uns por outros como marca do cinema de Debord (1991, tese 9) está em consonância com o que ele considera acerca das relações entre visível-invisível: "no mundo realmente invertido, o verdadeiro é momento do falso" 7 .

Debord nos oferece condições de refletir sobre a constituição das imagens e problematizá-las. Sabemos que o fetiche pelo poder configurou-se no fetiche pelo dinheiro, pelo consumo, de tal forma a ponto de entendermos que "o espetáculo é o capital a um tal grau de acumulação que se torna imagem" (DEBORD, 1991, tese 34) e essa imagem mostra apenas um lado de sua crueldade: o desejo e a sedução pelo consumo e deixa de lada todo o sofrimento que está por trás desse mesmo consumo.

${ }^{7}(0: 05: 20-0: 05: 25)($ tese 9$)$ 


\section{KLUGE: MEMÓRIA, PROJETO E PROJEÇÃO}

Alexander Kluge nos premia com um livro instigante, 120 Historias del cine, de difícil classificação no que tange ao caráter formal e profundamente crítico, pois circula por formatos diversos, entre o relato e o ensaio, promovendo instigantes ponderações em relação à história e à memória, na medida em que se faz marcado por uma escrita entreposta pelos liames da prosa com a reflexão crítica. 120 Historias del cine propõe uma recuperação da vida, de um projeto de criação e do bom trato com o fazer cinematográfico, por ser composto de fragmentos que destilam o pensamento de Kluge em relação à sétima arte, aguçado pela imaginação e pela lucidez analítica.

Fundamentalmente, o livro é uma história do cinema, mas, sobretudo, pensada pelo sentido de história a contrapelo, tal como definida por Walter Benjamin. Tanto que a edição em questão nos apresenta uma entrevista de Kluge, concedida a Carla Imbrogno, que revela sua visão contemporânea acerca da história do cinema:

Podemos hablar de 'reconstrucción' en este sentido: yo creo en la historia del
cine y en que hacer cine es algo mucho menos complicado que la industria
cinematográfica comercial. Nosotros podríamos ahora - nosotros dos - poner
aquí una cámara, rodar una película de cuatro horas e incluso subirla a YouTube.
Y eso probablemente sería parte de la historia del cine; eso sí, necesitamos
suerte, no podemos planificarlo (KLUGE, 2010, p. 306)

O cinema contemporâneo na era das redes sociais, da internet $3 G, 4 G$, popularizou mais que nunca a imagem. Entretanto, apesar de sua crescente disponibilidade pública a imagem ficou cada vez mais banalizada e espetacularizada, como destaca Maria Luiza Belloni, ao problematizar a questão. Diz Belloni (2003, p. 135): "a espetacularização do cotidiano nos reality shows (a banalização do banal, como diz Baudrillard, 2001); o jornalismo eletrônico (news all time, on line), uma proposta excessiva que lembra a pergunta tropicalista de Caetano Veloso: Quem lê tanta notícia?'. Essa pergunta colabora com o que Kluge (aponta como necessidade de sorte para que o cinema na era virtual possa se estabelecer e ser devidamente reconhecido como arte.

Mas, se há dificuldades para uma distinção do teor artístico do cinema nos meios digitais contemporâneos, imaginemos o quão difícil teria sido o caminho do cinema moderno. Esta forma de arte foi marcada pela necessidade de pensar, montar, colar. Ações que deveriam ocorrer conjuntas, quase automatizadas, em decorrência do apelo da máquina e do consumo fetichista do capitalismo. Para dar conta desses aspectos, Alexander Kluge arma-se da astúcia da ilusão e do recorte, que será o viés estético proposto por ele e por outros cineastas do Novo Cinema Alemão, como Reitz, Fassbinder e Schlondorff. Vale ressaltar que embora essa formulação estética e revolucionária voltada à ressignificação da imagem, não se torne exclusiva dos alemães, eles terão grande influência no desenvolvimento desse percurso libertário em relação à dimensões estéticas da sétima arte, uma vez que conseguem subverter projetos baseados na estereotipização e massificação, especialmente o da indústria cultural de Hollywood, tanto em meados do século XX, quanto em etapas posteriores. Um dos aspectos em destaque no Novo Cinema Alemão é o manuseio do tempo, que procuraremos salientar em Kluge.

Encontramos na filmografia de Kluge e em seu livro, diversas relações do cinema com a modernidade pontuando os conflitos presentes nessa relação, que estão ligados à ideia de linearidade. Refletir sobre a linearidade implica refletir também sobre o tempo, a memória e a história. Kluge acredita que o cinema deveria pensar o tempo sempre como algo no passado, mas interligado ao futuro. Para isso Kluge salienta ser necessário um projeto artístico que fosse baseado na desestabilização da ideia de tempo linear, possibilitando a costura entre passado e futuro em um complexo contexto do presente. 
Essa dimensão estética projeta-se sobre a dimensão ética defendida por Kluge, pois para ele o cinema deveria ser entendido como um fenômeno complexo diretamente ligado à construção de um produto utópico, produto sim, mas não de mercado, e sim a serviço da reflexão, do entendimento, da autonomia do sujeito. O cinema, tal como pensado por Kluge (2010, p.39), é uma máquina que suscita a imaginação e a emancipação, desse modo, ao analisar o cinema na esfera pública, diz ele: "solo a evidencia fílmica - eso ló sabíamos -, amansa la fantasia. Sin embargo, apenas existe material fílmico - ló aprendimos em esos dos dias - sobre cuestiones que han de decidirse em la esfera pública."

Para ilustrarmos esse debate entre o que se faz em cinema e o que escreve sobre cinema, conforme se encontra em Kluge (2001), tomaremos para análise uma de suas produções cinematográficas contemporâneas, intitulado Amor cego - Conversa com Jean-Luc Godard ${ }^{8}$, em que se destaca toda a estética de montagem e colagem, no ritmo alucinante da imagem que mistura a fantasia e a realidade, na medida em que manuseia formalmente a fusão de contornos textuais diversificados - reportagem, entrevista, ficção e biografia.

Ao contemplarmos esse filme é possível aproximarmos a imagem contemporânea, tal como já foi discutida em especial por Gilles Deleuze em Imagem-Movimento, da ideia de imagem ligada a uma atitude revolucionária, emancipadora, compreendida na escrita e na cinematografia de Kluge e Debord, uma vez ser saliente em ambos a necessidade da formação de uma imagem mental associada a um pensar acerca da sociedade que não está descolada de um pensar acerca da própria imagem. Vejamos como Deleuze (1983, p. 221 222, grifos do autor) analisa essa possibilidade:

\begin{abstract}
Quando falamos de imagem mental queremos dizer outra coisa: é uma imagem que toma por objetos de pensamento, objetos que têm uma existência própria fora do pensamento, como os objetos de percepção têm uma existência própria fora da percepção. É uma imagem que toma por objeto relações, atos simbólicos, sentimentos intelectuais. Ela pode ser, mas não é necessariamente, mais difícil que as outras imagens. Ela terá necessariamente com o pensamento uma nova relação, direta, inteiramente distinta daquela das outras imagens.
\end{abstract}

Esse é o caminho que encontramos na produção de Kluge e Debord. Uma cinematografia expressa pela imagem, não somente pela imagem, mas principalmente pelo que se pensa sobre essa imagem, por isso dizemos que as 120 histórias apresentadas por Kluge, em formato livro, são reflexões, memórias, anedotas e descrições técnicas próprias do cotidiano do cinema contemporâneo. Há no filme uma espécie de estrutura arqueológica envolvendo diversos momentos da vida do autor e do cinema, ou uma confusão entre a história do cinema e vida do autor. Há no sentido mais lacônico uma montagem ou uma remontagem da história como tempo e como indeterminação temporal do cinema-vida de Kluge. Esse percurso é algo predominante e recorrente no projeto criativo desse cineasta. Essa insistente relação entre o cinema e a reflexão sobre sua época também se encontra presente em "El amor es um instante, el arte es eterno", texto que reflete sobre o papel do cinema em tempos de guerra. Nele, Kluge (2010, p. 69) discute o cinema em meio a um cenário de destruição e tragédia:

${ }^{8}$ KLUGE, Alexander. Blinde Liebe-Gespräch mit Jean-Luc Godard. Produção: Kairos Film. Curta-metragem. DVD, 24 min, Alemanha, 2001. Disponível com legendas em espanhol em meio virtual: http://www.youtube.com/watch?v=V665vdzu-wI.

Este filme será apontado em nota no capítulo 7: Nadie quiere estar completamente a oscuras frente al televisor" vide: p. 278. Nesta nota encontramos parte da entrevista feita com Godard sobre o filme Elogio do Amor, base para a película de Kluge. 
La 'máquina de cine' rusa que surgió, autónoma, no toleró la frescura de los happy-ends. Antes bien, el 'arte de la vida' debía reproducir todos los enredos trágicos, si la idea era que el espectador abandonara la sala 'conmovido' y 'consolado'.

A opção pela produção de enredos trágicos capazes de comover e consolar o público é o que gera nossa percepção da cinematografia e da escrita de Kluge como verdadeiros capítulos-reflexão ou cenas-reflexão. Nisso reside o fio condutor de sua ideologia e a inclinação crítica, facilmente demarcadas nos sete capítulos que compõem o livro 120 Historias del cine. A forma de sua arte marca-se pela noção de fragmentação, bricolagem, montagem. Todas essas formas costumeiras de construir um todo por partes que ao mesmo tempo são independentes e dependentes. Por isso, consideramos que sejam bem mais que histórias, pensadas com o $\mathrm{H}$ maiúsculo dos manuais canônicos. A história proposta por Kluge está acompanhada de um teor testemunhal muito intenso, embebido no formato da narrativa de si, já que vincula o envolvimento com o cinema com suas vivências, essas marcadas por diversas contradições e paradoxos sobre o visível e o invisível, na medida em que sentimos também em Kluge a necessidade de especular acerca da sociedade da imagem.

Por sua vez, em Amor cego - Conversa com Jean-Luc Godard, ao tentar entender os processos estéticos desenvolvidos por Godard em Elogio ao Amor, Kluge abre a descrição com o efeito fundamental explorado pelo cineasta suíço: a colagem e a interposição de imagens, pondo em evidência a impossibilidade de definição de passado e presente, pois ambos parecem, ao mesmo tempo, presente e passado. Com cores ou sem cores temos um forte efeito de indefinição, perseguido tanto por um quanto por outro.

O filme de Kluge (2001) é, além de um diálogo intertextual, uma grande incursão pela estética criadora de Jean Luc Godard, pois busca extrair do diretor confissões sobre sua proposta estética a partir do confronto entre a história do cinema, as histórias de Elogio do Amor - filme de Godard - e o enredo de Amor Cego, filme de Kluge, na tentativa de fazer confrontar sua produção com a produção de Godard, como parte de um pensar sobre o amor, em conflito com a sociedade contemporânea. Durante a entrevista, por exemplo, Kluge pede para Godard definir o que significaria para ele a expressão "amor-cego", considerando uma ambivalência com o cinema, pois para ele "se dice que el amor es ciego, es dicir que amamos sin hacer preguntas [...] Las películas de las que hablábamos no estaban distribuídas, nadie podia verlas. Amábamos esas películas ciegamente.” (KLUGE, 2010, p. 278)

De sua parte o filme de Godard desafia o espectador, já que se utiliza da montagem como estratégia para dar sentido a um todo inacabado, fazendo com que as partes contribuam para a aparição de algo que não se encontrava em nenhuma delas, por isso o filme é bem mais que uma história a ser contada. É também uma reflexão sobre como uma história pode ser contada e isso se traduz no que vemos na tela. Nela, encontramos dois pontos temporais distintos, um no passado em cores, outro no presente, em preto e branco, desconstruindo a ideia de passado e presente, apontando assim uma perspectiva de futuro, já que nossa visão passa a ser composta por ilusões responsáveis pela constituição das sensações da invisibilidade espetacular.

Essa estratégia espetacular que funde as imagens em uma só, trazendo a ilusão de um todo - e de um tempo - complexo, permite ao expectador destituir-se da obrigação de concentrar-se em um enredo linear e claro e perambular pelo fragmentário. Nesse sentido, podemos entender que o cineasta busca fazer com que em sua narrativa o passado explique o presente do filme, explique o conflito experimentado pelo personagem Edgar, e do mesmo modo o conflito da humanidade diante da indagação o que é ser humano?, na medida em que vai buscar na Segunda Guerra Mundial e na história da resistência o caminho para entender o presente e a impotência diante do capital. Do ponto de vista da foram, retoma a 
teoria de Pasolini, referente ao uso da montagem como instrumento de construção do sentido, pois tal película é composta não por imagens concentradas em si mesmas mas, sobretudo, articuladas por meio de ecos, circulações, desejos arquitetados pelos fluxos entre as imagens.

Por todo esse conjunto de aspectos, é possível afirmarmos que o filme de Kluge trata de se armar dos vários dispositivos para trazer a seu público o desnudamento dessas estratégias de composição utilizadas pelo cineasta, na tentativa de criar uma narrativa a respeito do amor, que está além de uma história de amor ou sobre o amor, pois ao longo do filme assoma principalmente a especulação sobre o papel da História e do lugar do homem nesta sociedade do espetáculo, quando não há preocupação com as pessoas, com os sentimentos, com o comprometimento com a humanidade, por isso, a narrativa considera que o amor é cego.

Essas constituintes se encontram igualmente projetadas no livro de Kluge e, portanto, em sua escrita. A busca por construir uma história que siga os mesmos parâmetros do filme de Godard também se faz presente em 120 Historias del cine, na medida em que constrói um paralelo entre uma história do amor e uma história do cinema. Nessa trajetória o diálogo com a história também se encontra favorecido. De fato, fechando o sexto capítulo intitulado "La Bomba em la oficina imperial de indemnizaciones", temos um cenário de guerra, que volta à baila diante da necessidade de mostrar o cinema também como lugar da resistência:

Sin Duda, no el desconcertante argumento, donde el amor de la bella heredera por el renegado de su esposo (no se ve a menudo que algo tan valioso como ella sea "abandonado y desechado") se expresa en el hecho de que ella ayuda a la amante de su esposo (en solidaridad con él, no con ella) a obtener una última victoria. Las imágenes eran fuertes, dijo el capitán. Pero más fuerte era la impresión causada por el recinto que había perdido su techo y para el cual un nuevo bombardeo difícilmente supusiera una amenaza adicional. (KLUGE, 2010, p 205-206)

O momento da projeção, mesmo diante do medo, do horror, da incerteza e do abandono gerados pela guerra, nos trás uma interessante compreensão de que "el cine es más bien un 'instante em si imposible': antes de produzirse, uno no se lo habría imaginado así; después, no admite repetición" (KLUGE, 2010, p. 206).

Esse seria, para ambos, Kluge e Godard, o verdadeiro cinema.

\section{REFERÊNCIAS}

BELLONI, M. L. (Org.) A formação na sociedade do espetáculo. São Paulo: Loyola, 2003.

DEBORD, Guy. Comentaires sur la société du spectacle. Paris: Gérard Lebovici, 1998.

A sociedade do espetáculo. Lisboa: Mobilis in Mobile, 1991.

A sociedade do espetáculo: comentários sobre a sociedade do espetáculo. Tradução de Estela dos Santos Abreu. Rio de Janeiro: Contraponto, 1997.

DELEUZE, Gilles. Cinema: a imagem movimento 1. Tradução: Stella Senra. São Paulo: Brasiliense, 1983. 
FREIRE FILHO, João. A sociedade do espetáculo revisitada. Revista FAMECOS, n. 22. Porto Alegre, dezembro de 2003.

KLUGE, Alexander. Blinde Liebe- Gespräch mit Jean-Luc Godard. Produção: Kairos Film. Curta-metragem. DVD, 24 min, Alemanha, 2001. Disponível em: <http://www.youtube.com/watch?v=V665vdzu-wI >. Acesso em: 10 out. 2013.

KLUGE, Alexander. 120 histórias del cine. Buenos Aires: Caja Negra, 2010.

Alexander Kluge: o quinto ato. Organização: Jane de Almeida. Tradução: George Sperber. São Paulo: Cosac Naify, 2007.

KOCH, Gertrudes. Percursos subterrâneos do Capital: uma entrevista com Alexander Kluge. Disponível em: http://revolucoes.org.br/v1/sites/default/files/percursos_ subterraneos_do_capital.pdf. Acesso em: 11 out. 2013.

SCHØLLHAMMER, Karl Erik. Além do visível: o olhar da literatura. Rio de Janeiro: Letras, 2007.

Recebido em 02/07/2013.

Aprovado em 12/09/2013. 